\title{
Pandemic (HINI) 2009 Cases in Nepal
}

\author{
Kandel N, ${ }^{1}$ Shrestha JM, ${ }^{2}$ Upadhyay $B,{ }^{3}$ Shrestha $\mathrm{AK}^{2}{ }^{2}$ Shakya $\mathrm{G}^{3}$ \\ 'Disease Surveillance and Epidemiology, WHO, Nepal, ${ }^{2}$ Avian Influenza Control Project, Department of Health Services, \\ Ministry of Health \& Population, Nepal, ${ }^{3}$ National Public Health Laboratory, Department of Health Services, Ministry of \\ Health \& Population, Nepal.
}

\begin{abstract}
We analyzed the data available in Nepal during this pandemic in order to determine the epidemiological, clinical and virological characteristics of pandemic influenza A in 2009. The test was conducted by real-time Reverse Transcription - Polymerase Chain Reaction on sample from patients with suspected influenza-like illnesses. Out of 538 cases were tested, $32 \%$ were positive for pandemic influenza A 2009 and the infection rate was highest for cases of 11-20 years and lowest in $>50$ years of age.
\end{abstract}

Keywords: influenza A ; pandemic; RT-PCR; surveillance.

\section{INTRODUCTION}

A novel influenza $A(\mathrm{H} 1 \mathrm{~N} 1)$ virus has been detected in mid-April 2009 in US and Mexico. This virus has spread rapidly among humans worldwide. ${ }^{1,2}$ The pandemic H1N1 2009 virus is a unique combination of gene segments from North American and Eurasian swine lineages and ancestral genes derived from avian humans and species. ${ }^{3,4}$ In Kathmandu, Nepal, the first laboratoryconfirmed case of pandemic H1N1 2009 was detected in June, 2009, in a patient who had returned from the United States. Since then till September, another 30 cases were imported from abroad. In October, evidence of local transmission has been established in the country and entry screening has been stopped. The public health response included voluntary self-isolation or hospital isolation and oseltamivir treatment of suspected and confirmed patients. Despite these interventions, cases increased gradually not rapidly in general population.
In November, number of confirmed cases increased in various districts of Nepal. Few suspected cases of Pandemic H1N1 2009 were admitted in major hospitals from Kathmandu, Chitwan and Lalitpur and some of them needed intensive care management.

National Public Health Laboratory has been designated by Ministry of Health and Population for diagnosing pandemic H1N1 2009 virus infections. To strengthen the capacity of National Public Health Laboratory, Center for Disease Control, Atlanta, USA has provided the required reagents and primers for Reverse Transcriptase - Polymerase Chain Reaction through active facilitation by World Health Organization Nepal.

Correspondence: Dr. Nirmal Kandel, World Health Organization, Indonesia. Email: kandeln@searo.who.int 
This report describes epidemiological, clinical and virological findings for the cases of pandemic H1N1 2009 diagnosed in Nepal.

\section{METHODS AND FINDINGS}

All suspected cases from entry screening, various hospitals and health centers were enrolled for the study. Study patients were enrolled from June 2009, when the pandemic phase 6 has been declared by World Health Organization (WHO) to March 2010. ${ }^{5}$ Samples have been collected from the suspected influenza like illnesses from; entry screening, hospitals and various outbreaks. During the study period, respiratory samples from 538 patients were submitted to National Public Health Laboratory (NPHL) virology laboratory for pandemic H1N1 2009 testing. Nasopharyngeal/throat or tracheal aspirates were obtained from patients and shipped to NPHL in viral transport media. Epidemiologic and demographic parameters and information on clinical signs, underlying disease, and medication use were obtained for each patient.

A laboratory diagnosis of influenza infection was determined by real-time Reverse Transcription-PCR (RT-PCR), by using the Centers for Disease Control and Prevention's protocol, on a real-time rotary analyzer (Rotor-Gene 6000, Rcorbet Research, Australia). ${ }^{6}$ The QIAamp Viral RNA Mini Kit (QIAGEN, Valencia, CA, USA) was used to extract RNA.

Community transmission was not established till September and it was decided to conduct a cross sectional study at four major hospitals of Kathmandu Valley. Study was carried out in last week of September. Attending physicians of these hospitals selected patients who presented with influenza like illnesses. Throat swabs were taken by a trained technician from 42 patients. A detailed history of travel and contact with ill persons or those who had recently traveled abroad was also collected. Three samples gave a positive result for Pandemic H1N1 2009. These cases were traced back and it was confirmed no history of travel to affected countries or contact with any confirmed cases. This study has helped to determine that community transmission of Pandemic H1N1 2009 is actually occurring in Nepal, which assisted government to immediately start the containment and community mitigation activities and further intensify surveillance activities to detect new cases and identify affected areas. This small but well planned research study gave results that immediately altered the national action plan for H1N1 influenza by discontinuing entry screening thus allowing spared manpower for intensified surveillance activities. Of 538 patients, 172 (32 \%) had positive results for influenza subtype $\mathrm{H} 1 \mathrm{~N} 1$ by $\mathrm{RT}-\mathrm{PCR}$. Of these
172 case-patients, 149 (87\%) were outpatients and 23 (13\%) were hospital inpatients. Pandemic (H1N1) 2009 was detected most frequently among patients of 11 - 20 years age group 51 (30\%), followed by 21 30 years age group $46(27 \%)$ and $0-10$ years age group $41(24 \%)$. The lowest number of cases was detected in $51-60$ years age group $4(2 \%)$ and $>60$ years 4 ( $2 \%)$. In addition, prevalence of cases in $31-40$ years age group and 41 - 50 years age group is similar with $13(8 \%)$. However, mean age for this infection is 21 years. By sex, male were 118 (69\%) and female were $54(31 \%)$ (Figure 1).

Age-wise distribution of pandemic H1N1 (2009) case in Nepal

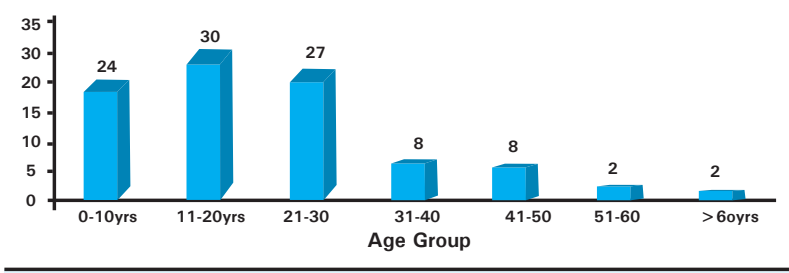

Figure 1. Age-wise Distribution of Pandemic H1N1 (2009) cases in Nepal

According to district wise distribution of the cases, most of the cases were detected in cities of Kathmandu, Kaski, Chitwan and Parbat districts. In other places sporadic cases were found. Ministry of Health and Population (MoHP) have made strategy to test only suspected cases on following conditions: to identify new geographical location, random sampling of cases during outbreaks and hospital admitted cases due to constrains of laboratory resources. Hence, these cases don't represent the actual number of cases. However, all outbreaks of influenza like illnesses and febrile illnesses have been investigated for possible infection of pandemic H1N1 (Figure 2).

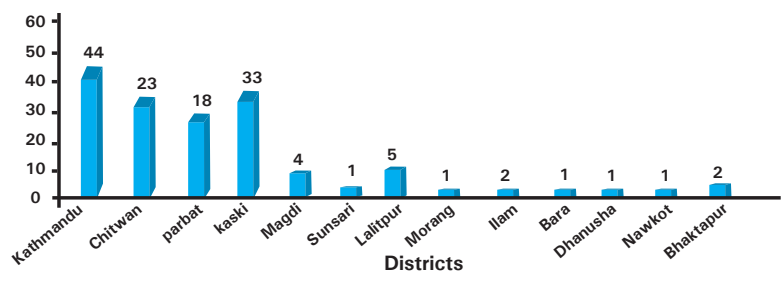

Figure 2. District-wise Case Distribution

On looking monthly distribution of cases, it has been observed that most of the cases were detected during the period of winter season from October to January. The cases which were detected since June to September were detected from entry screening and their close contacts.

Symptomatically more dominant symptoms of these cases were fever 151 (88\%); cough 154 (90\%); sore 
throat $113(66 \%)$; headache $86(50 \%)$; rhinorrhea 72 $(42 \%)$; muscle pain/myalgia $89(52 \%)$ and dyspnea 32 (19\%) (Figure 3).

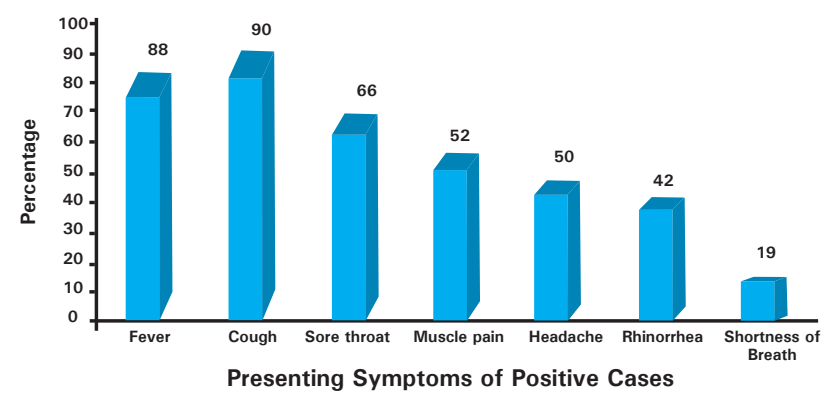

Figure 3. Presenting symptoms of positive cases

Few cases were admitted in various hospitals. Out of 23 cases, which were admitted in various hospitals three had a fatal outcome. One of the cases was pregnant mother, one was admitted case with acute renal failure and other one had no underlying conditions. Rests of the cases were well managed in respiratory infection wards ${ }^{9}$ and in intensive care units $^{8}$ of various hospitals. The average period of ICU admission was 10 days (ranging from $6-21$ days). All the patients who were admitted in the ICU went through mechanical ventilation. The most common diagnosis was consolidation of the lungs which progresses very rapidly. Some of the patients with fatal outcome have shown widespread diffuse consolidation of the lungs.

\section{CONCLUSIONS}

From June 2009 to March 2010, pandemic (H1N1) 2009 virus was detected in 32\% of respiratory samples submitted to NPHL. This percentage is similar to the overall percentage reported from countries like
Bangladesh. 7,8 Majority of patients were from 1120 years of age, which is different than other recent studies, where predominant age group is $21-30$ years of age. 7,9 Male are predominantly affected in Nepal, which is similar to other studies. ${ }^{7,10,11}$ The lowest rate of infection has been seen for the patients above 50 years of age. This result might imply that persons in this age group were formerly exposed, through infection to an influenza $A(\mathrm{H} 1 \mathrm{~N} 1)$ virus that is genetically and antigenically more closely associated to pandemic (H1N1) 2009 than to other new influenza A viruses. ${ }^{13}$ Presenting symptoms of these cases were similar with that of many findings. ${ }^{7}$

Nepal has also reported majority of cases from the urban settlements like districts of Kathmandu valley, Pokhara (Kaski), and Chitwan, which is similar to other cities across the globe, however, not like that of New York City and Mexico City. ${ }^{14}$ Dense population structure and active life of people of cities may have increased the risk of transmission of the infection.

\section{ACKNOWLEDGMENTS}

We would like to thank Manas K Banerjee, Niti Sedhain, Raj Kumar Mahato, and staff of Avian Influenza Control Project for their technical support. We would like to appreciate WHO Nepal for continuous technical and financial assistance to AICP. We also thank staff of Epidemiology and Disease Control Division for their active participation on surveillance, preparedness and response activities; staff of National Public Health Laboratory for their contribution on testing these samples; staff from various hospitals, who have reported and managed the serious cases; and all the district health offices and respective regional health directorate for their support on outbreak investigation and response.

\section{REFERENCES}

1. Centers for Disease Control and Prevention. 2009. Update: novel influenza A (H1N1) virus infections - worldwide May 6, 2009. MMWR Morb. Mortal Wkly Rep. 58:453-48.

2. Peiris JS, Poon LL, Guan Y. Emergence of a novel swine-origin influenza A virus (S-OIV) H1N1 virus in humans. J Clin Virol. 2009;45:169-73.

3. Garten RJ, Davis CT, Russel CA, Shu B, Lindstrom S, Balish $\mathrm{A}$, et al. Antigenic and genetic characteristics of swine-origin 2009 A (H1N1) influenza viruses circulating in humans. Science. 2009;325:197-201.
4. Chen GW, Shih SR. Genomic signatures of influenza A pandemic (H1N1) 2009 virus. Emerg Infect Dis. 2009;15:1897-903

5. World Health Organization. Global alert and response. Current WHO phase of pandemic alert. [Online]. 2010[cited 2010 Apr 29]. Available from: http://www.who.int/csr/ disease/avian_influenza/phase/en

6. Rcorbet Research - A Division of Corbett Life Science. Rotor-Gene 6000-real time rotary analyzer. [Online]. 2010[cited 2010 Apr 29]. Available from: http://www. genehk.com/pdf/Rotor-Gene-6000.pdf 
7. Islam QT, Kahhar A, Arif SM et.al. Epidemiological Profile of Pandemic Influenza A (H1N1) 2009 at Dhaka Medical College Hospital. J Medicine. 2010;11:3-6.

8. Chowell G, Bertozzi SM, Colchero MA, Lopez-Gatell H, Alpuche-Aranda C, Hernandez M, et al. Severe respiratory disease concurrent with the circulation of H1N1 influenza. $\mathrm{N}$ Engl J Med. 2009;361:674-9.

9. Bin C, Xing WL, Mao Y et al. Clinical features of the initial cases of 2009 pandemic influenza A (H1N1) virus infection in China. N Engl J Med. 2009;361:1-11.
10. Novel Swine-Origin Influenza A (H1N1) Virus Investigation Team. Emergence of a novel swine origin influenza A (H1N1) virus in humans. N Engl J Med. 2009;360:2605-15.

11. Trifonov V, Khiabanian H, Greenbaum B, Rabadan R. The origin of the recent swine influenza $\mathrm{A}(\mathrm{H} 1 \mathrm{~N} 1)$ virus infecting humans. Euro Surveill. 2009 Apr 30;14(17).

12. Echavarria M, Querci M, Marcone D et. al. Pandemic (H1N1) 2009 Cases, Buenos Aires, Argentina. Emerg Infect Dis. 2010;16(2).

13. Bell DM, Weisfuse BIB, Hernandex-Avila M. Pandemic Influenza as 21st Century Urban Public Health Crisis. Emerg Infect Dis. 2009;15(12). 